\title{
Alopecia-intellectual disability syndrome
}

INSERM

\section{Source}

INSERM. (1999). Orphanet: an online rare disease and orphan drug data base. Alopeciaintellectual disability syndrome. ORPHA:2850

Alopecia-intellectual deficit syndrome is an extremely rare syndrome described in less than 20 families to date and characterized by total or partial alopecia associated with intellectual deficit. The syndrome can be associated with other anomalies such as seizures, sensorineural hearing loss, delayed psychomotor development, and/or hypertonia. 